\title{
Study on Affective Factors in College English Teaching and Learning
}

\author{
Yu Qiutan \\ Feixian Campus, Linyi University, Linyi, Shandong, China \\ fxyuqiutan@163.com
}

\begin{abstract}
With the rise and development of humanistic psychology, the teaching concept of "learner centered" is being highly rewarded and respected, then foreign language teaching researchers also begin to pay close attention to the influence of affective factors in language learning. Developing "whole person" is the goal of humanistic psychology, and it advocates unifying cognition and emotion. But for a really long time, there are two misunderstandings of our English teaching. First, Chinese English educators and teachers have just paid main attentions on training students' cognitional ability but neglected the function of affective factors influenced during the teaching and learning procedure and also underestimate the effectiveness of affects played during the teaching and learning process, which ultimately leads to affective illiteracy. Second, even with the guidance of all those existing teaching theories and methodologies, the reality of Chinese English teaching and the students' practical English skills are still not satisfactory because the college English class is usually teacher-centered, text-translation and students passively followed, which finally reduces students' interests in learning English. Yet, psychological researches have already confirmed a strong dynamic affect and positive emotions such as interest; self-esteem will have a direct role in language acquisition whereas negative emotions such as anxiety, fear, tension will hinder the learning effectiveness.
\end{abstract}

Keywords: Affective factors, Learning motivation, College English teaching.

\section{Introduction}

The famous educator Chan Korsakov pointed out that "teaching method, once the students hit the emotion and will, touch their spiritual needs, this kind of teaching can play a highly effective role." in the past, people used to discuss the cognitive factors of language, pay little attention to the research of emotional factors, but the research value of affective factors as cognitive factors value. So linguists believe that affective factors in second language acquisition and cognitive factors at least as large, and often more. But in the actual education, there is too much emphasis on rational and cognitive functions of the brain and ignored the non-rational, not pay attention to the emotional factors of students' learning, resulting in "emotional blank", thus resulting in a considerable part of the students the tendency of language learning is to emphasize the cognitive factors of language learning and ignore the influence of affective factors on language learning.

Educational psychology research shows that emotion is a dynamic system of cognitive activity, cognitive activities of the organizers, plays a role in cognitive motivation and organizational activities, decided to approach or avoid situations, and people are willing to pay more cognitive effort in different areas. The role of the learner's emotional state directly influence to their learning behavior and learning results. Positive emotions can create a favorable learning psychological state, while negative emotions will affect the normal development of learning potential. At present, experimental study is "Happy Teaching" or "Happy Education" in some schools of our country, has made gratifying achievements, which is starting from the emotional factors.

How to construct positive affective factors in College English Teaching, the author believes that the following aspects:

\section{Stimulate Students' Intrinsic Motivation In English Learning}

Pay attention to fostering students' intrinsic motivation, plays a vital role in improving college students' English learning quality. Mobilize students' intrinsic motivation is each teacher's responsibility, teachers should understand the learners' personality, attitude, interest, emotion and 
learning strategies, students can learn a language consciously learning and confidence. Interest in learning motivation mainly comes from the heart, which forced the learning motivation and persuasion mainly from outside interference and pressure.

\section{(1).Stimulating students' intrinsic motivation through autonomous learning}

The core content of autonomous learning is to let students grasp their own learning. The emotion in the first place is the primary characteristic of self-regulated learning. Modern learning theory, autonomous learning does not mean that the individual learning independent learning. On the contrary, autonomous learning between students is to rely on and mutual cooperation is the premise of students can according to their own the need and desire to control the learning content and process. Therefore, autonomy is a kind of mechanism, is a kind of emotion, the emotional existence and reflect the relationship between groups must have support, including support between the students and teachers support students. Support refers to the collective cooperation, classroom interaction, mutual communication and mutual learning support for teachers is not only to give students care, inspiration, induction and cultivation of students' autonomous awareness, but also should help students develop and implement learning plan and evaluation.

(2).Through cooperative learning to reduce language anxiety, language inhibition, improve students' learning efficiency

Cooperative learning is a kind of group, team members can effectively improve their academic performance, enhance self-esteem, self-confidence, a successful teaching strategy and learning motivation. Through cooperative learning, learners' anxiety reduction, there is an important reason is because each learner in cooperative learning is a member of the group and a sense of belonging. Therefore, teachers can use cooperative learning and help students build up confidence in learning English, reduce excessive anxiety and inhibition of language, clear the appropriate anxiety is helpful to English learning, intrinsic motivation to learn English well.

\section{Teachers Change Their Teaching Concepts and Their Roles}

(1).Strengthen the awareness of the influence of affective factors on language learning

In the role of teachers, should also do the following three changes the traditional classroom teaching in the "knowledge" to "help" or "guide", becomes a simple class" organizer "for the activities of the" communication partners ", change the pure classroom" control "for the students' psychological the treatment". In exchange, teachers pay attention to students' emotional expression and emotional release, treat the students with a sincere attitude, as a collaborator with the student thought of equal dialogue, in the dialogue to the students with knowledge and emotional inspiration to help them overcome the negative affective factors in English learning. Care for students is the basis and premise of the education of students, only in this way, in order to better mobilize the students The positive emotion, and thus infected students, guide students to give positive feedback, to cultivate students' positive attitude towards English learning

(2).The implementation of appreciation education for students, and enhance the confidence of introverted students

Appreciation education should be open, so that those who receive the greatest psychological satisfaction, get more confidence. Appreciation education can strengthen students' self-esteem. In the teaching, the teacher should respect and trust the students, take care of the students' self-esteem, because everyone has a form of self concept, and let others recognized needs. The teacher is not stingy praise for their praise and encouragement, is usually more effective than criticism. Students should try to find every point in the progress of learning, encourage students to use English to communicate.

\section{Pay Attention to The Emotional Problems Caused By Different Levels of Teaching}

The implementation of College English teaching at different levels should not only arouse the students' intelligence, but also stimulate the students' Non intelligence factors. Mobilize the students' 
emotional factors, we can mobilize the enthusiasm of learning, the release of potential, to solve the learning process of psychological, ideological problems.

(1).The implementation of teaching objectives, appropriate respect for the wishes of students

The implementation of College English teaching must first achieve the hierarchical teaching objectives, because the single teaching target makes teachers cannot attend every student, to reflect the dominant position of teachers and students' subject status. For students of different levels to formulate different teaching objectives. Teachers should learn to control and regulation, when students have anxiety, in the process of teaching in frustration, irritability situation, teachers are the organizers of teaching activities, we should pay attention to students' affective factors and regulation. The teachers in the classroom to get all the emotions and thoughts has nothing to do with teaching temporarily sealed, never let your mood affect the classroom teaching.

(2).Develop the emotional resources of the various levels of teaching materials, the cultivation of emotional attitude in the classroom teaching

First of all, to do the language point of learning and emotional attitude of the organic combination of training. The primary task of English courses is to develop students' ability to use language comprehensively. In order to deepen the understanding and master the basic usage of language points, teachers often need to provide some examples or context.

Secondly, when presenting new language knowledge to students, the teacher should associate the content of the teaching with the knowledge and life experiences of the student, especially by creating some "real" activities that enable students to clearly learn what language they can do The Only in this way will the students take the initiative to participate in the study and use English in the process of participating in the study.

\section{Create a Harmonious English Learning Environment}

The humanistic teaching theory of American humanistic education expert Rodgers pointed out that the establishment of harmonious teacher-student relationship, create a mutual learning environment, not only can make the classroom teaching smoothly, also can help students develop a healthy personality. To make full use of foreign language learning is flexible. The time and place on the characteristics of English learning into the students' learning, life, rest and entertainment in various places, the students organized a variety of curricular and extracurricular activities, try to create a harmonious environment for English learning, so that students often are involved in English, play a subtle role.

\section{(1).Make full use of existing teaching resources}

Firstly, sponsored by the Department of language teachers' organization, develop a students, feasible and can persevere plan. Encourage the class English subscribe to newspapers and magazines, to carry out the English reading report at the oral English contest, speech contest, essay exchange activities give full play to the role of school radio station.

Secondly, the modernization of teaching the technology and means of teaching, including teaching equipment, teaching equipment and teaching modernization.

Finally, teachers take various measures to strengthen the language teaching in the classroom teaching, teachers should do everything possible to create opportunities for students to practice.

\section{(2).Teachers should increase their emotional input to students}

Teachers in the emotional awareness of each student is an independent individual, has its unique character, mental state and learning strategies and motivation of teachers. All students should take and accept the attitude of tolerance, considering everyone's emotional space. Students will make mistakes, students' mistakes taunt, hurt students' self-esteem is bound to destroy the students, the most precious thirst for knowledge and curiosity. Teachers should have a correct understanding of making mistakes is the only way which must be passed for students to learn language, reduce the students to use the target language is afraid of making mistakes psychological pressure. 


\section{Summary}

The various proposals are intrinsically linked to each other and form a complete system. Regardless of the way to stimulate and cultivate the positive emotions of college students' English learning, the ultimate goal is to make college students in English learning to achieve "cognitive" and "emotional" two aspects of unity, which requires teachers to update their own ideas in teaching. The students as a thought, an emotional individual, try a variety of channels and forms to stimulate students' intrinsic motivation to learn English, to fully tap and develop the emotional resources in the discourse, from the language knowledge and discourse content two dimensions To develop emotional teaching, the emotional attitude of the infiltration in the various levels of teaching in all aspects of training students positive emotional factors, students learning interest, learning initiative and enthusiasm to achieve joint participation of teachers and students, and harmonious development, thereby enhancing the Comprehensive Quality of College Students' English.

\section{References}

[1] Liu Runqing, Dai manchun A study on the current situation and development strategies of foreign language teaching reform in Chinese Universities. Beijing: Foreign Language Teaching and Research Press, 2014.6

[2] Liang Yan A study of English teaching methods through affective factors in second language acquisition. Technology wind 2009.20

[3] Li Yincang On the affective goal of foreign language teaching, Shanghai: Shanghai foreign language teaching press 2015.8

[4] Jane Arnold. Affect in Language Learning. Beijing: Foreign Language Teaching and Research Press, 2000. 12

[5] Zhao Xia The present situation and implementation strategies of affective education in English Teaching, Education and occupation, 2006(8):112-113

[6] Jeremy Harmer. The Practice of English Language Teaching London: Longman. 2003,182. 